\title{
Article
}

\section{Two New Species of Fibrodontia (Trechisporales, Basidiomycota) with a Key to Worldwide Species}

\author{
Shi-Liang Liu ${ }^{1}$, Shuang-Hui He ${ }^{2}$, Dong-Mei Liu ${ }^{3}$ and Li-Wei Zhou ${ }^{1, *}$ \\ 1 State Key Laboratory of Mycology, Institute of Microbiology, Chinese Academy of Sciences, \\ Beijing 100101, China; liushiliang@im.ac.cn \\ 2 School of Ecology and Nature Conservation, Beijing Forestry University, Beijing 100083, China; \\ heshuanghui@bjfu.edu.cn \\ 3 The Institute of Ecology, Chinese Research Academy of Environmental Sciences, Beijing 100012, China; \\ ldmgenetics@163.com \\ * Correspondence: liwei_zhou1982@im.ac.cn
}

check for updates

Citation: Liu, S.-L.; He, S.-H.; Liu, D.-M.; Zhou, L.-W. Two New Species of Fibrodontia (Trechisporales, Basidiomycota) with a Key to Worldwide Species. J. Fungi 2021, 7, 982. https://doi.org/10.3390/ jof7110982

Academic Editors: Samantha C.

Karunarathna and

Saowaluck Tibpromma

Received: 1 November 2021

Accepted: 18 November 2021

Published: 18 November 2021

Publisher's Note: MDPI stays neutral with regard to jurisdictional claims in published maps and institutional affiliations.

Copyright: (c) 2021 by the authors. Licensee MDPI, Basel, Switzerland. This article is an open access article distributed under the terms and conditions of the Creative Commons Attribution (CC BY) license (https:/ / creativecommons.org/licenses/by/ $4.0 /)$.

\begin{abstract}
Fibrodontia is a genus of wood-inhabiting fungi consisting of four species so far, including F. gossypina as generic type. Two new species, Fibrodontia austrosinensis and F. subalba, are described and illustrated from China. Fibrodontia austrosinensis from southwestern China is characterized by a grandinioid to odontioid hymenophore with numerous small aculei, a dimitic hyphal system with scattered, smooth skeletal hyphae and ellipsoid basidiospores measuring 4.2-5.2 × 3.5-4.5 $\mu \mathrm{m}$. Fibrodontia subalba from the West Tianshan Mountain in northwestern China is distinguished by an odontioid to hydnoid hymenophore, a dimitic hyphal system, and ellipsoid basidiospores measuring 3.7-4.4 $\times 2.8-3.4 \mu \mathrm{m}$. The phylogenies inferred from the data set of nuc rDNA ITS1-5.8S-ITS2 (ITS) and D1-D2 domains of nuc 28S rDNA (28S), and that of ITS, 28S, translation elongation factor (tef1 $\alpha$ ), and RNA polymerase II second largest subunit ( $r p b 2)$ supported Fibrodontia as a monophyletic genus in the Trechisporales, and F. austrosinensis and F. subalba as separate lineages within Fibrodontia. Multi-rate Poisson Tree Processes, Automatic Barcode Gap Discovery and genetic distance methods based on ITS sequences of Fibrodontia also supported F. austrosinensis and F. subalba as distinct species. The taxonomic status of F. fimbriata that was recently transferred from Cystidiodendron, is briefly discussed. A key to all six known species of Fibrodontia is provided.
\end{abstract}

Keywords: 2 new taxa; corticioid fungi; Cystidiodendron; Hydnodontaceae; taxonomy; wood-inhabiting fungi

\section{Introduction}

Fibrodontia Parmasto, introduced for F. gossypina Parmasto [1], resembles Hyphodontia J. Erikss. by its resupinate, light-colored basidiocarps with odontioid hymenophores, clamped generative hyphae, and hyaline, thin-walled basidiospores. However, the presence of skeletal hyphae and the absence of cystidia distinguish Fibrodontia from Hyphodontia [2]. Eriksson et al. believed that Fibrodontia was closely allied to Hyphodontia [2] and Langer considered it a synonym of Hyphodontia [3]. Surprisingly, molecular phylogenetic studies place these genera in different orders-Fibrodontia in the trechisporoid clade in the Hydnodontaceae Jülich, Trechisporales K.H. Larss. [4,5], and Hyphodontia in the Hyphodontiaceae Xue W. Wang \& L.W. Zhou, Hymenochaetales Oberw. [6].

Besides Fibrodontia gossypina, the generic type, the genus includes Fibrodontia brevidens (Pat.) Hjortstam \& Ryvarden, F. tomentosa (Berk. \& M.A. Curtis) Hjortstam \& Ryvarden, and F. alba Yurchenko \& Sheng H. Wu [7,8]. Of the four species currently accepted in Fibrodontia, F. alba and F. brevidens are reported from China [8-10].

During a study of wood-inhabiting fungi in China, two undescribed species of Fibrodontia were identified based on morphological criteria and molecular genetic analyses. The primary purpose of this study is to use an integrative taxonomic approach for the delimitation and description of two new species of Fibrodontia from China. 


\section{Materials and Methods}

\subsection{Morphological Examination}

The studied specimens, deposited in the fungarium of Institute of Microbiology, Chinese Academy of Sciences (HMAS), and the herbarium of Beijing Forestry University (BJFC), were macromorphologically observed with the aid of a Leica M 125 stereomicroscope (Wetzlar, Germany) at magnifications up to $100 \times$. Special color terms followed Kornerup and Wanscher [11]. The microscopic procedure followed Wang et al. [12]. Specimen sections were mounted in Cotton Blue (CB, $0.1 \mathrm{mg}$ aniline blue dissolved in $60 \mathrm{~g}$ pure lactic acid), Melzer's reagent (1.5 g potassium iodide, $0.5 \mathrm{~g}$ crystalline iodine and $22 \mathrm{~g}$ chloral hydrate dissolved in $20 \mathrm{~mL}$ distilled water) or $5 \%$ potassium hydroxide $(\mathrm{KOH})$, then examined with an Olympus BX43 light microscope (Tokyo, Japan) at magnifications up to $1000 \times$. All measurements were taken from the sections mounted in CB. When reporting the variation in the size of the basidiospores, $5 \%$ of measurements were excluded from each end of the range and are given in parentheses. $L$ stands for mean basidiospore length (arithmetic average of all basidiospores), W for basidiospore width (arithmetic average of all basidiospores), $\mathrm{Q}$ for variation in the ratio of $\mathrm{L}$ to $\mathrm{W}$ among the studied specimens, and $\mathrm{n}(\mathrm{a} / \mathrm{b})$ for number of basidiospores (a) measured from given number of specimens (b). Drawings were made with the aid of a drawing tube.

\subsection{DNA Amplification and Sequencing}

Total DNA was extracted from selected specimens using the CTAB rapid plant genome extraction kit (Aidlab Biotechnologies Co., Ltd., Beijing, China) according to the manufacturer's instructions. The nuc rDNA ITS1-5.8S-ITS2 (ITS) region was amplified with primers ITS5 and ITS4 [13], the D1-D2 domains of nuc 28S rDNA (28S) with primers LR0R and LR7 [14], the translation elongation factor (tef1 $\alpha$ ) with primers 983F and 1567R [15], and the RNA polymerase II second largest subunit ( $r p b 2)$ with primers RPB2-f5F and RPB2-b7.1R [16,17] using 2×EasyTaq ${ }^{\circledR}$ PCR SuperMix (TransGen Biotech Co., Ltd., Beijing, China). The PCR procedure was as follows: for ITS and tef $1 \alpha$, initial denaturation at $95^{\circ} \mathrm{C}$ for $3 \mathrm{~min}$, followed by 35 cycles at $94{ }^{\circ} \mathrm{C}$ for $40 \mathrm{~s}, 54^{\circ} \mathrm{C}$ for $45 \mathrm{~s}$ and $72{ }^{\circ} \mathrm{C}$ for $1 \mathrm{~min}$, and a final extension of $72{ }^{\circ} \mathrm{C}$ for $10 \mathrm{~min}$; for $28 \mathrm{~S}$, initial denaturation at $94{ }^{\circ} \mathrm{C}$ for $1 \mathrm{~min}$, followed by 34 cycles at $94{ }^{\circ} \mathrm{C}$ for $30 \mathrm{~s}, 50^{\circ} \mathrm{C}$ for $1 \mathrm{~min}, 72{ }^{\circ} \mathrm{C}$ for $1.5 \mathrm{~min}$, and a final extension of $72{ }^{\circ} \mathrm{C}$ for $10 \mathrm{~min}$; for $r p b 2$, initial denaturation at $94{ }^{\circ} \mathrm{C}$ for $2 \mathrm{~min}$, followed by 10 cycles at $94{ }^{\circ} \mathrm{C}$ for $45 \mathrm{~s}, 60^{\circ} \mathrm{C}$ for $45 \mathrm{~s}$ (minus $1{ }^{\circ} \mathrm{C}$ per cycle) and $72{ }^{\circ} \mathrm{C}$ for $1.5 \mathrm{~min}$, then followed by 36 cycles at $94{ }^{\circ} \mathrm{C}$ for $45 \mathrm{~s}, 53{ }^{\circ} \mathrm{C}$ for $1 \mathrm{~min}$ and $72{ }^{\circ} \mathrm{C}$ for $1.5 \mathrm{~min}$, and a final extension of $72{ }^{\circ} \mathrm{C}$ for $10 \mathrm{~min}$. The PCR product was sequenced with the same primers used in PCR amplification at the Beijing Genomics Institute, China. The newly generated sequences were submitted to GenBank (http:/ / www.ncbi.nlm.nih.gov/genbank; Table 1).

Table 1. Sequences used in the phylogenetic analyses.

\begin{tabular}{|c|c|c|c|c|c|}
\hline \multirow{2}{*}{ Species } & \multirow{2}{*}{ Voucher Number } & \multicolumn{4}{|c|}{ GenBank Accession Number } \\
\hline & & ITS & $28 S$ & tef $1 \alpha$ & $r p b 2$ \\
\hline Brevicellicium exile & MA:Fungi:76132 & HE963779 & - & - & - \\
\hline \multirow{7}{*}{ Fibrodontia alba } & TNM F24944 & NR153983 & NG060401 & - & - \\
\hline & EYu 110703-25 & КС928274 & КС928275 & - & - \\
\hline & EYu 110417-10 & JQ612713 & JQ612714 & - & - \\
\hline & He 4761 & MK204529 & MK204541 & MW478697 & MW478705 \\
\hline & LWZ 20170820-34 & MT802108 & MT802102 & MW478698 & MW478706 \\
\hline & LWZ 20180923-4 & MT802107 & MT802101 & MW478696 & MW478704 \\
\hline & CLZhao 3488 & MK268910 & - & - & - \\
\hline \multirow[t]{3}{*}{ Fibrodontia austrosinensis } & LWZ 20190820-11b & MT802111 & MT802105 & MW478700 & MW478709 \\
\hline & He 3453 & MT802109 & MT802103 & - & MW478708 \\
\hline & He 6283 & MT802110 & MT802104 & MW478699 & MW478710 \\
\hline
\end{tabular}


Table 1. Cont.

\begin{tabular}{|c|c|c|c|c|c|}
\hline \multirow{2}{*}{ Species } & \multirow{2}{*}{ Voucher Number } & \multicolumn{4}{|c|}{ GenBank Accession Number } \\
\hline & & ITS & $28 S$ & tef1 $\alpha$ & $r p b 2$ \\
\hline \multirow[t]{3}{*}{ Fibrodontia brevidens } & Wu 9807-16 & KC928276 & KC928277 & - & - \\
\hline & He 3559 & MK204528 & - & MW478701 & MW478707 \\
\hline & CLZhao 3417 & MK268911 & - & - & - \\
\hline \multirow[t]{2}{*}{ Fibrodontia gossypina } & AFTOL-ID 599 & DQ249274 & AY646100 & - & - \\
\hline & GEL 5042 & - & AJ406421 & - & - \\
\hline Fibrodontia subalba & Dai 15931 & MT802106 & MT802100 & - & - \\
\hline Hyphodontia subalutacea & GEL 2196 & DQ340341 & DQ340362 & - & - \\
\hline Hyphodontia floccosa & Berglund 150-02 & DQ873618 & DQ̊873618 & - & - \\
\hline Porpomyces submucidus & Dai 13708 & KT152144 & KT152146 & MW478702 & - \\
\hline Sistotremastrum suecicum & KHL 11849 & EU118666 & EU118667 & - & - \\
\hline Sistotremastrum sp. & LWZ 20191107-25 & MW474864 & MW477771 & MW478703 & MW478712 \\
\hline Subulicystidium longisporum & KHL 14229 & MH000601 & MH000601 & - & - \\
\hline Subulicystidium tropicum & He 3968 & MK204531 & MK204544 & - & MW478711 \\
\hline Trechispora echinospora & E $11 / 37-12$ & JX392853 & JX392854 & - & - \\
\hline Tubulicium vermiferum & KHL 8714 & - & AY463477 & - & - \\
\hline
\end{tabular}

The newly generated sequences are in boldface.

\subsection{Phylogenetic Analyses}

To explore the phylogenetic position of the newly sequenced Chinese specimens, a combined data set of ITS and 28S region adapted from the data sets used in Yurchenko and $\mathrm{Wu}$ [8] and Liu et al. [10] was employed. This updated data set included all main lineages in Trechisporales as ingroup taxa with Hyphodontia subalutacea (P. Karst.) J. Erikss. and H. floccosa (Bourdot \& Galzin) J. Erikss. from Hymenochaetales as outgroup taxa. A second data set with a combination of ITS, 28S, tef1 $\alpha$ and $r p b 2$ region was used to further explore the relationships of the newly sequenced Chinese specimens within Fibrodontia. Besides species of Fibrodontia, other related taxa in Hydnodontaceae with at least one of tef1 $\alpha$ and $r p b 2$ region available were included. An unnamed species of Sistotremastrum J. Erikss. with a separate family position from Hydnodontaceae in Trechisporales [5] was selected as the outgroup taxon. A third data set with the ITS region of Fibrodontia was used to confirm the species independency.

Of the three data sets, each gene region was separately aligned using MAFFT 7.110 [18] with the G-INS-i strategy [19] and then concatenated to three alignments accordingly. The resulting alignments were deposited at TreeBase (http: / / www.treebase.org; submission ID S27597). The best-fit evolutionary model for each gene region of the three alignments was separately estimated using jModelTest 2.1.10 [20,21]. Following these models, Bayesian inference (BI) and maximum likelihood (ML) algorithms were used to performed phylogenetic analysis. BI was conducted using MrBayes 3.2.7a [22]. Two independent runs were employed. Each run started from random trees and had 1,000,000 generations. Trees were sampled every 1000 th generation. The first $25 \%$ of sampled trees were discarded as burn-in, whereas all remaining trees were used to construct a $50 \%$ majority consensus tree and for calculating Bayesian posterior probabilities (BPPs). Chain convergence was determined using Tracer 1.7 [23]. ML analysis was performed using raxmlGUI 2.0 [24,25] and bootstrap (BS) replicates were evaluated under the auto FC option [26].

Regarding the tree inferred from the data set of ITS region, species delimitation was further estimated using multi-rate Poisson Tree Processes (mPTP) [27] with default parameters and Automatic Barcode Gap Discovery (ABGD) [28] with $P_{\min }=0.01, P_{\max }=0.1$, steps $=20, X$ (relative gap width $)=1.5, \mathrm{Nb}$ bins (for distance distribution) $=20$ and JukesCantor model (JC69). In addition, interspecific and intraspecific genetic distances of ITS sequences were calculated from the alignment of the data set of ITS region using MEGA $X$ [29] with a bootstrap method of variance estimation in 1000 BS replications, a $p$-distance substitution model, the uniform rates among sites, and a pairwise deletion treatment. 


\section{Results}

The data set of ITS and $28 \mathrm{~S}$ region included 22 ITS and $2128 \mathrm{~S}$ sequences from 24 samples, and resulted in an alignment of 2011 characters. The data set of ITS, 28S, tef1 $\alpha$ and $r p b 2$ region included 12 ITS, 12 28S, eight tef $1 \alpha$ and nine $r p b 2$ sequences from 14 samples, and resulted in an alignment of 3115 characters. The data set of ITS region with 15 samples and resulted in an alignment of 593 characters. The ML searches for the data sets of ITS and $28 \mathrm{~S}$ region, ITS, 28S, tef1 $\alpha$ and $r p b 2$ region and ITS region stopped after 200, 100 and 350 replicates, respectively. For BI, GTR + I + G was estimated as the best-fit evolutionary model for the data sets of ITS and 28S region and ITS, 28S, tef1 $\alpha$ and rpb2 region, while HKY + I as that for data set of ITS region. For the three data sets, all chains in BI converged after 1,000,000 generations, where the effective sample sizes of all parameters were greater than 400 and the potential scale reduction factors approached 1.000. Because BI and ML algorithms generated nearly congruent topologies, the ML trees are presented with BS values and BPPs greater than 50\% and 0.8, respectively, shown at the nodes (Figures 1-3).

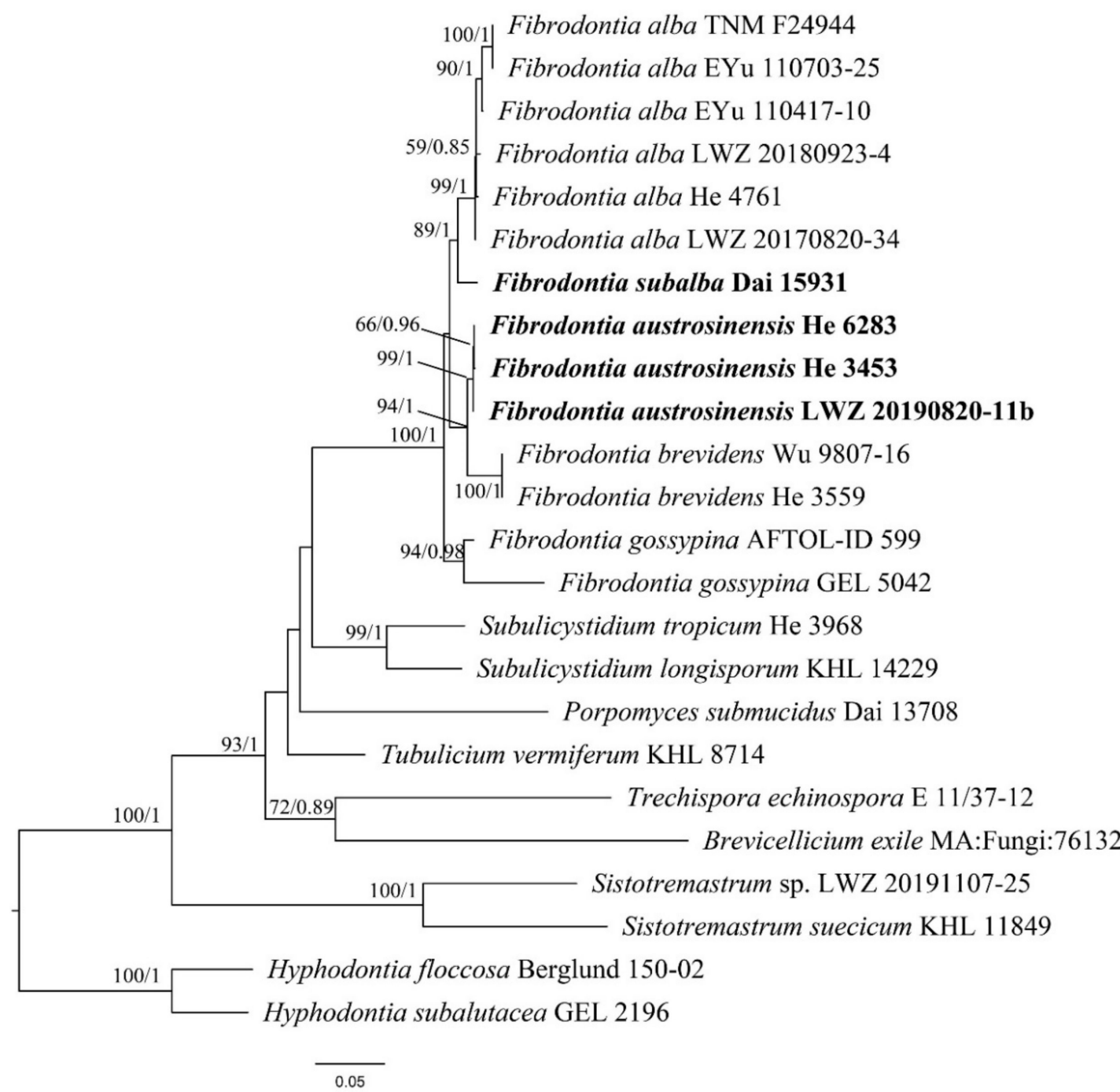

Figure 1. Phylogenetic position of Fibrodontia austrosinensis and F. subalba inferred from the data set of ITS and 28S region. The topology is from maximum likelihood analysis. Bootstrap values and Bayesian posterior probabilities, if simultaneously above $50 \%$ and 0.8 , respectively, are labelled at the nodes. The newly described species are in boldface. 


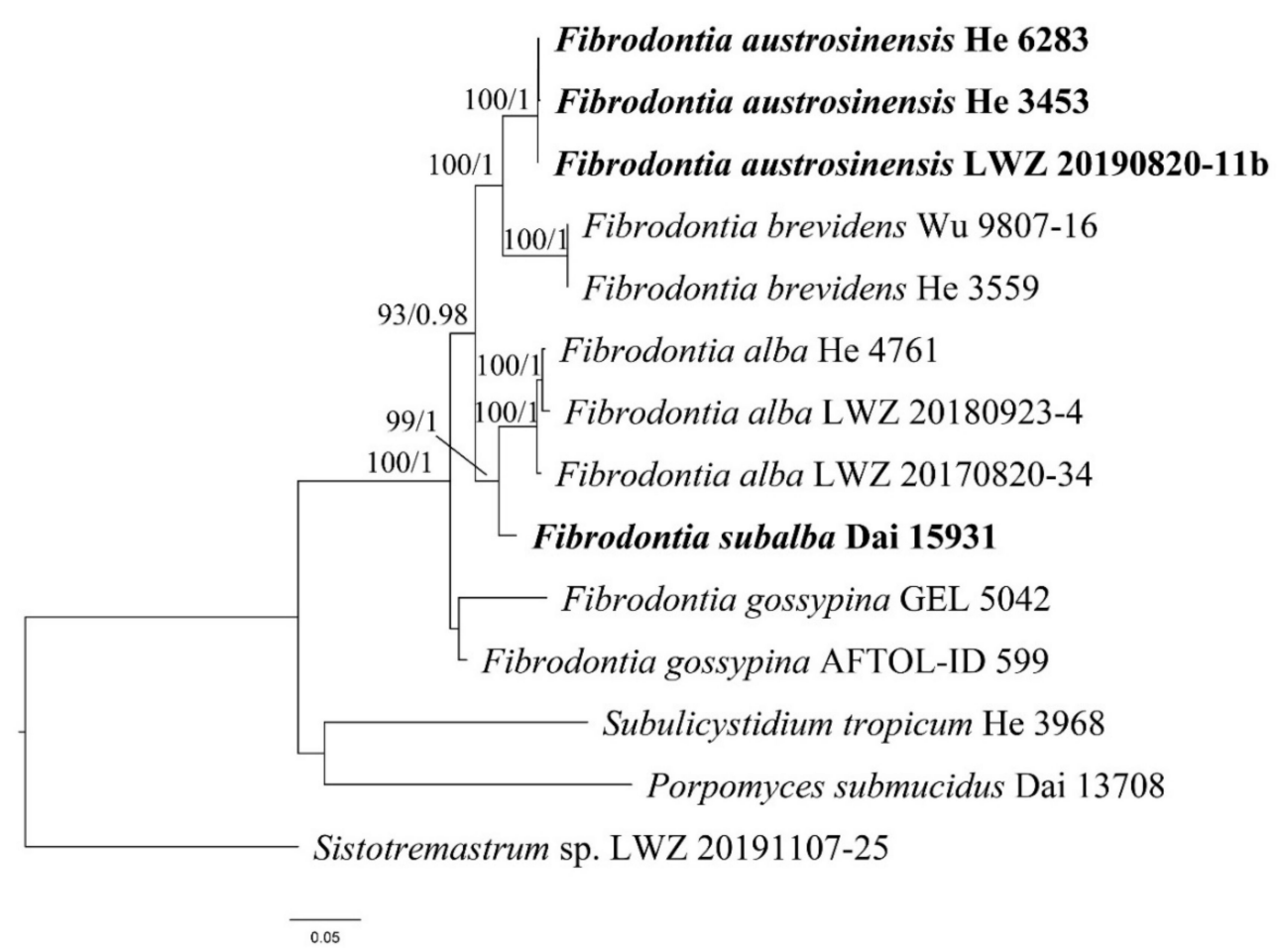

Figure 2. Phylogenetic position of Fibrodontia austrosinensis and F. subalba inferred from the data set of ITS, 28S, tef1 $\alpha$, and $r p b 2$ region. The topology is from maximum likelihood analysis. Bootstrap values and Bayesian posterior probabilities, if simultaneously above $50 \%$ and 0.8 , respectively, are labelled at the nodes. The newly described species are in boldface.
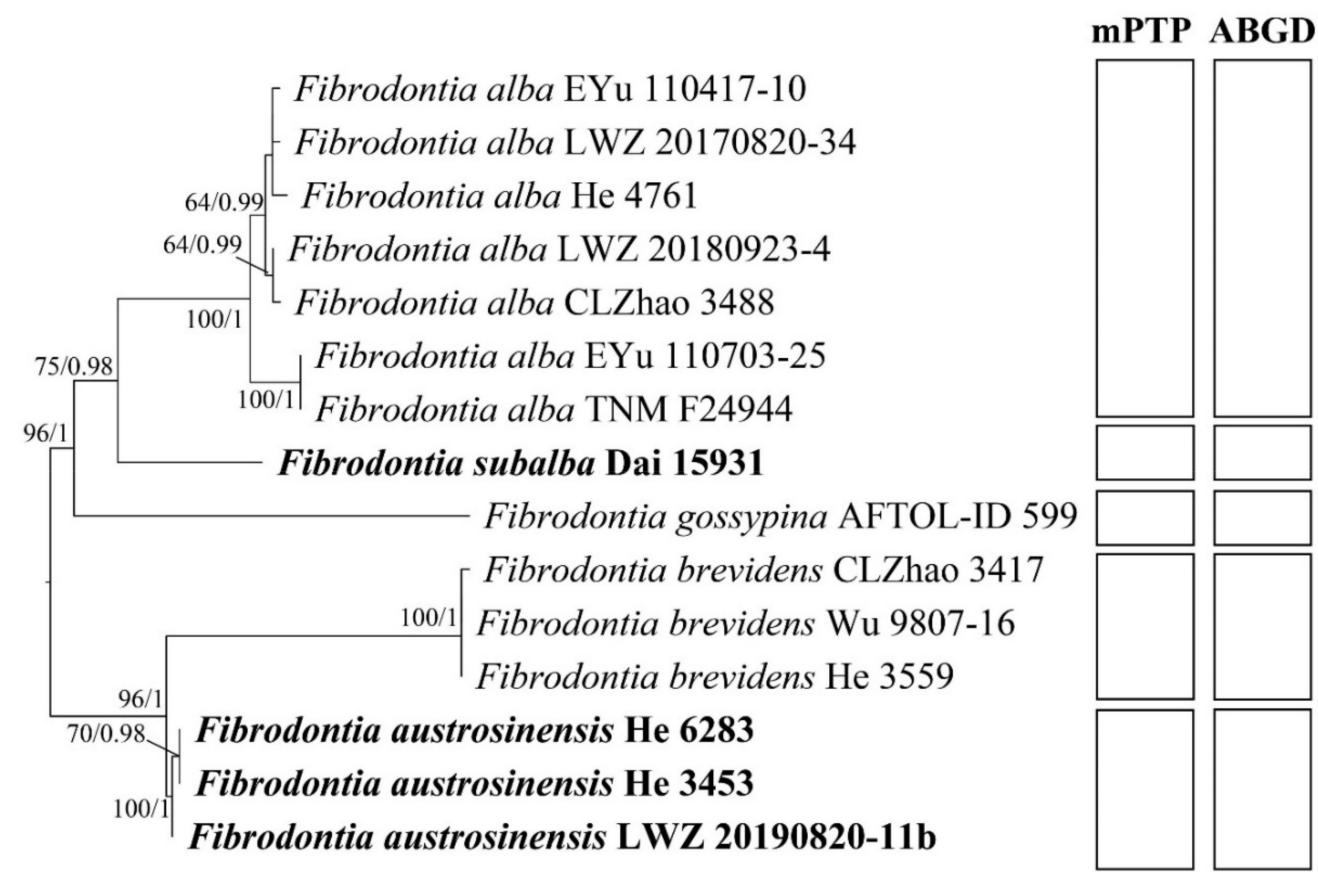

Figure 3. Phylogenetic relationship of species within Fibrodontia inferred from the data set of ITS region. The topology is from maximum likelihood analysis. Bootstrap values and Bayesian posterior probabilities, if simultaneously above $50 \%$ and 0.8 , respectively, are labelled at the nodes. The newly described species are in boldface. Species delimitation indicated by rectangles was inferred using the multi-rate Poisson Tree Processes (mPTP) and the Automatic Barcode Gap Discovery (ABGD) methods. 
The phylogeny inferred from the data set of ITS and 28S region (Figure 1) recovered Fibrodontia as a monophyletic genus within Trechisporales. The phylogenies inferred from the data sets of ITS and 28S region (Figure 1) and ITS, 28S, tef1 $\alpha$ and rpb2 region (Figure 2) both recovered F. alba, F. brevidens and F. gossypina as distinct lineages. In addition, Dai 15,931 from northwestern China represented a distinct lineage sister to F. alba (BS $=89 \%, \mathrm{BPP}=1.00$ in Figure 1; $\mathrm{BS}=99 \%, \mathrm{BPP}=1.00$ in Figure 2) and three samples from southwestern China, viz. He 3453, He 6283, LWZ 20190820-11b, formed a strongly supported lineage sister to F. brevidens (BS $=94 \%, B P P=1.00$ in Figure $1 ; B S=100 \%, B P P=1.00$ in Figure 2). The midpoint-rooted phylogenetic tree inferred from the data set of ITS region strongly supported the independence of each species, which strictly corresponded to the species delimitation inferred using mPTP and ABGD methods (Figure 3). Moreover, the mean values of genetic distances calculated from the data set of ITS region between the species of Fibrodontia ranged from $5.54 \%$ to $10.45 \%$, compared to intraspecific distances of $0.06 \%$ to $1.17 \%$ (Table 2). Taking morphological characters into consideration, these two new lineages represent new species that are described below.

Table 2. Genetic distances of ITS sequences between and within species of Fibrodontia.

\begin{tabular}{lcccccc}
\hline & Species & $\mathbf{1}$ & $\mathbf{2}$ & $\mathbf{3}$ & $\mathbf{4}$ & $\mathbf{5}$ \\
\hline 1 & F. alba & 0.0117 & & & & \\
2 & F. subalba & 0.0554 & n.a. & & & \\
3 & F. brevidens & 0.0719 & 0.0758 & 0.0006 & & \\
4 & F. austrosinensis & 0.0554 & 0.0592 & 0.0530 & 0.0012 & \\
5 & F. gossypina & 0.0879 & 0.0903 & 0.1045 & 0.0781 & n.a. \\
\hline
\end{tabular}

The mean values of genetic distances between species are shown below the diagonal, and those within species are shown in italic along the diagonal.

\section{Taxonomy}

Fibrodontia austrosinensis S.L. Liu, S.H. He \& L.W. Zhou, sp. nov. (Figure 4A,B and Figure 5)
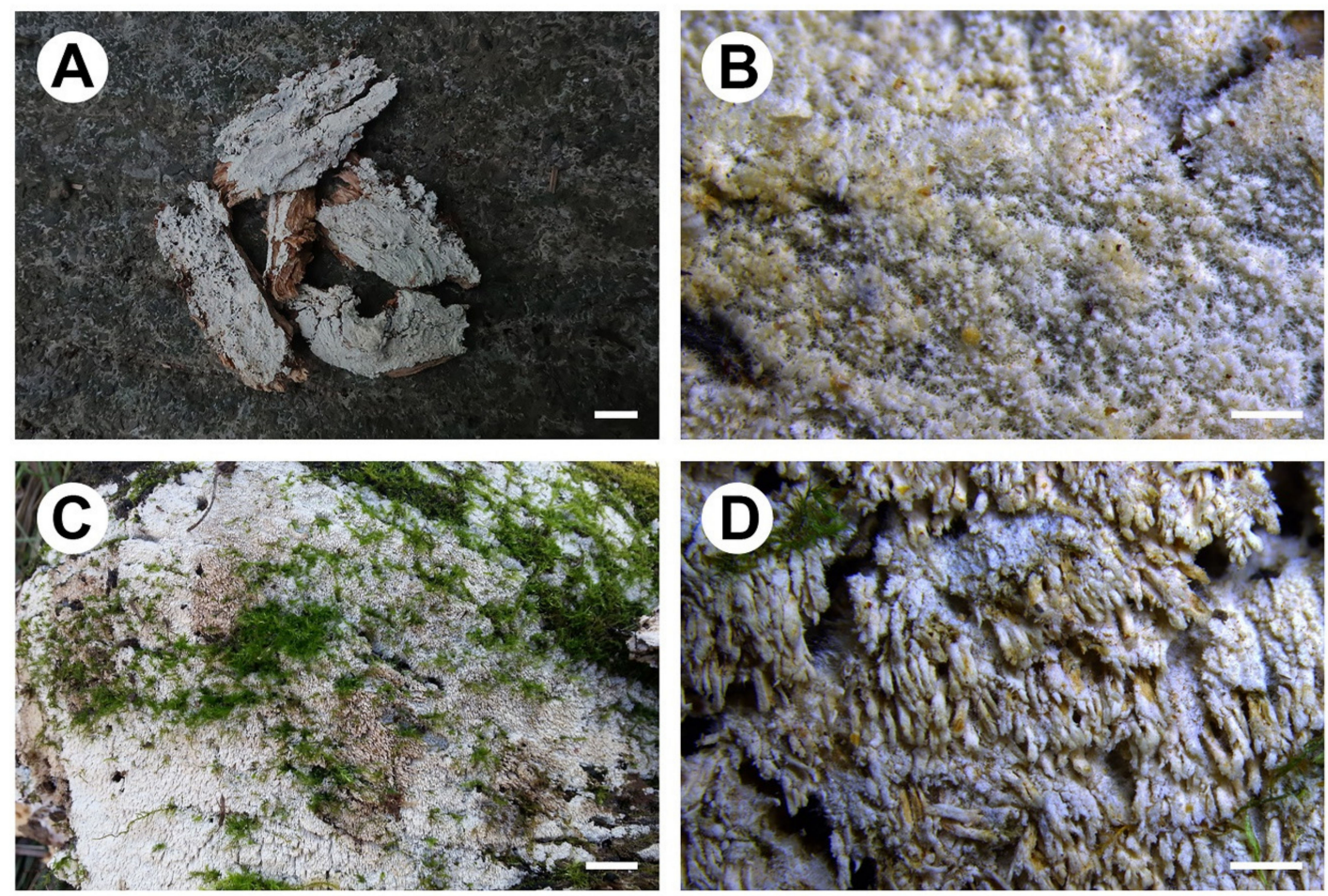

Figure 4. Basidiocarps of Fibrodontia. (A,B) F. austrosinensis (holotype); (C,D) F. subalba (holotype).-Scale bars: $(\mathbf{A}, \mathbf{C})=1 \mathrm{~cm}$; (B) $=0.5 \mathrm{~mm} ;(\mathbf{D})=1 \mathrm{~mm}$. 

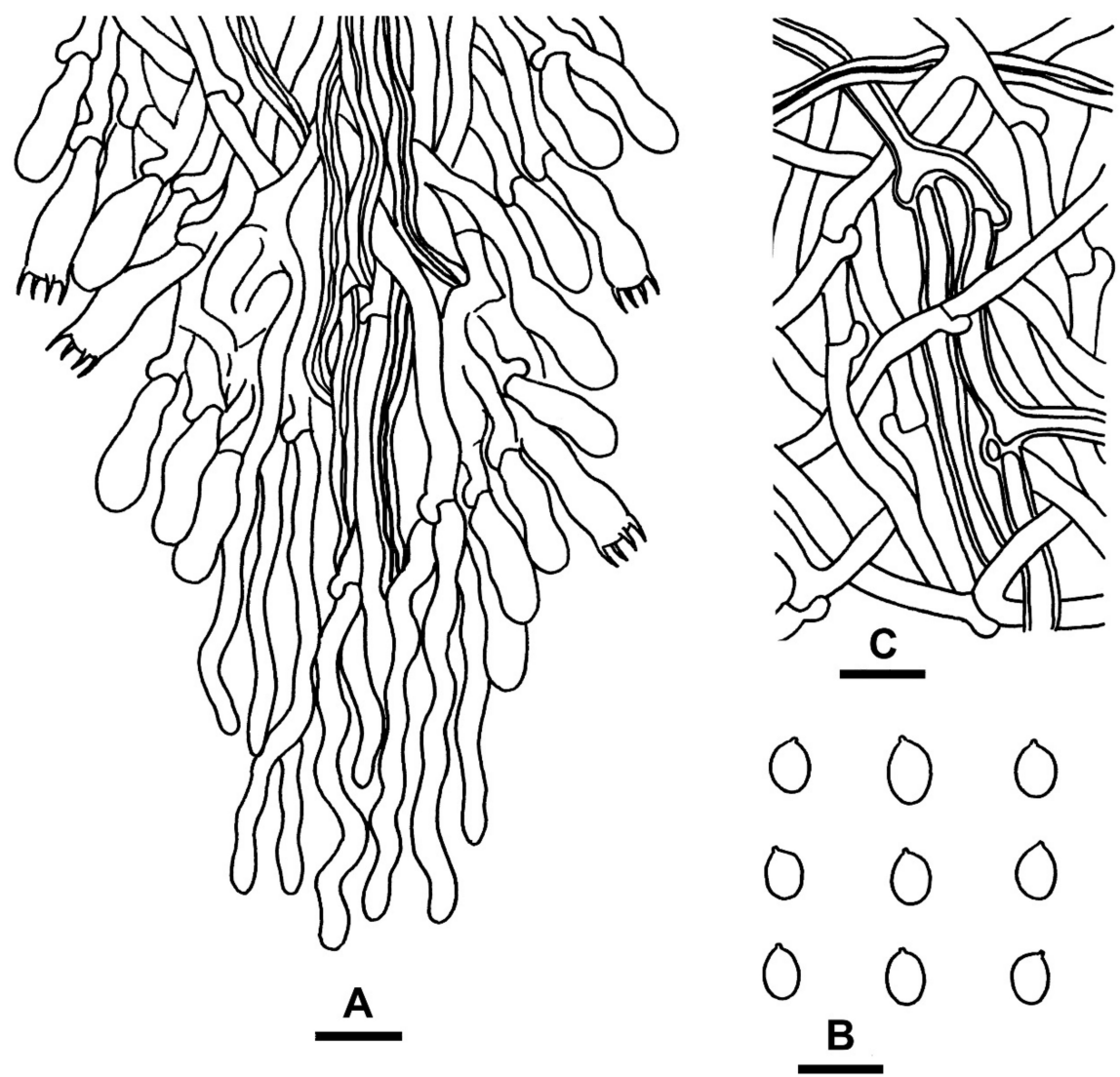

Figure 5. Microscopic structures of Fibrodontia austrosinensis (drawn from the holotype). (A) Part of the vertical section of basidiocarp; (B) basidiospores; (C) hyphae from subiculum. Scale bars: $(\mathbf{A}, \mathbf{B}, \mathbf{C})=10 \mu \mathrm{m}$.

\section{MycoBank: MB 836338.}

Etymology: austrosinensis (Latin), refers to the distribution in southern China.

Type: China, Sichuan, Pingshan County, Laojunshan National Nature Reserve, $104^{\circ} 4^{\prime} \mathrm{E}$, $28^{\circ} 40^{\prime} \mathrm{N}$, on rotten wood of angiosperm, 20 August 2019, L.W. Zhou, LWZ 20190820-11b (holotype HMAS).

Description: Basidiocarps annual, resupinate, inseparable from substrate, without odor or taste, soft corky, and brittle when dry, up to $8 \mathrm{~cm}$ long, $4 \mathrm{~cm}$ wide and $0.5 \mathrm{~mm}$ thick. Hymenophore grandinioid to odontioid with numerous small aculei, darkening but otherwise unchanged in $\mathrm{KOH}$. Aculei orange white (5A2), greyish-orange (5B6) to yellowish brown (5D5) when fresh, greyish orange (5B3) to brownish orange [5C(3-4)] when dry, apically slightly fimbriate, up to $0.4 \mathrm{~mm}$ long. Subiculum white to cream, up to $100 \mu \mathrm{m}$ thick. Margin white, cottony, up to $0.5 \mathrm{~mm}$ wide. Hyphal system dimitic; generative hyphae with clamp connections. Subiculum composed of a loose layer of distinct hyphae; generative hyphae, hyaline, thin- to slightly thick-walled, occasionally branched, smooth, 2-3.5 $\mu \mathrm{m}$ in diam; skeletal hyphae rare, hyaline to yellowish, thick-walled with a wide to narrow lumen, unbranched, smooth, slightly flexuous, loosely interwoven, 2-3 $\mu \mathrm{m}$ in diam. Aculei composed of a central core of compact hyphae and subhymenial and hymenial layers, at apex terminal hyphae slightly tapered; generative hyphae distinct, hyaline, thin- to slightly thick-walled, occasionally branched, smooth, interwoven, 2-3 $\mu \mathrm{m}$ in diam; skeletal hyphae rare, hyaline to yellowish, thick-walled with a wide to narrow lumen, unbranched, smooth, slightly flexuous, more or less parallel along the aculei, 2-3 $\mu \mathrm{m}$ in diam. Basidia suburniform to clavate, thin-walled, with four sterigmata and a clamp connection at base, 13-16 $\times 4.5-5.5 \mu \mathrm{m}$; basidioles similar in shape to basidia, but smaller. Basidiospores ellipsoid to ovoid, hyaline, thin-walled, smooth, inamyloid, indextrinoid, acyanophilous, $(4-) 4.2-5.2(-5.5) \times(3-) 3.5-4.5(-4.8) \mu \mathrm{m}, \mathrm{L}=4.8 \mu \mathrm{m}, \mathrm{W}=3.9 \mu \mathrm{m}, \mathrm{Q}=1.2-1.3(n=90 / 3)$. 
Other specimens (paratypes) examined: China, Yunnan, Tengchong County, Laifengshan Forest Park, $98^{\circ} 29^{\prime}$ E, $25^{\circ} 1^{\prime} \mathrm{N}$, on rotten wood of angiosperm, 1 Dec. 2015, S.H. He, He 3453 (BJFC); Xichou County, Xiaoqiaogou Forest Park, $104^{\circ} 41^{\prime}$ E, $23^{\circ} 21^{\prime} \mathrm{N}$, on rotten wood of angiosperm, 16 Nov. 2019, S.H. He, He 6283 (BJFC).

Notes: Fibrodontia austrosinensis resembles species of Hyphodontia s.l., since it has grandinioid to odontioid hymenophore with numerous, short aculei and ellipsoid basidiospores. However, development of skeletal hyphae in the subiculum and aculei trama places this taxon in Fibrodontia. Fibrodontia brevidens resembles F. austrosinensis but differs in producing slightly longer aculei, up to $0.7 \mathrm{~mm}$ long, moderately encrusted skeletal hyphae, and shorter, subglobose basidiospores $(4-4.5 \times 3.5-4.5 \mu \mathrm{m})$ [3].

Fibrodontia subalba S.L. Liu \& L.W. Zhou, sp. nov. (Figure 4C,D and Figure 6)
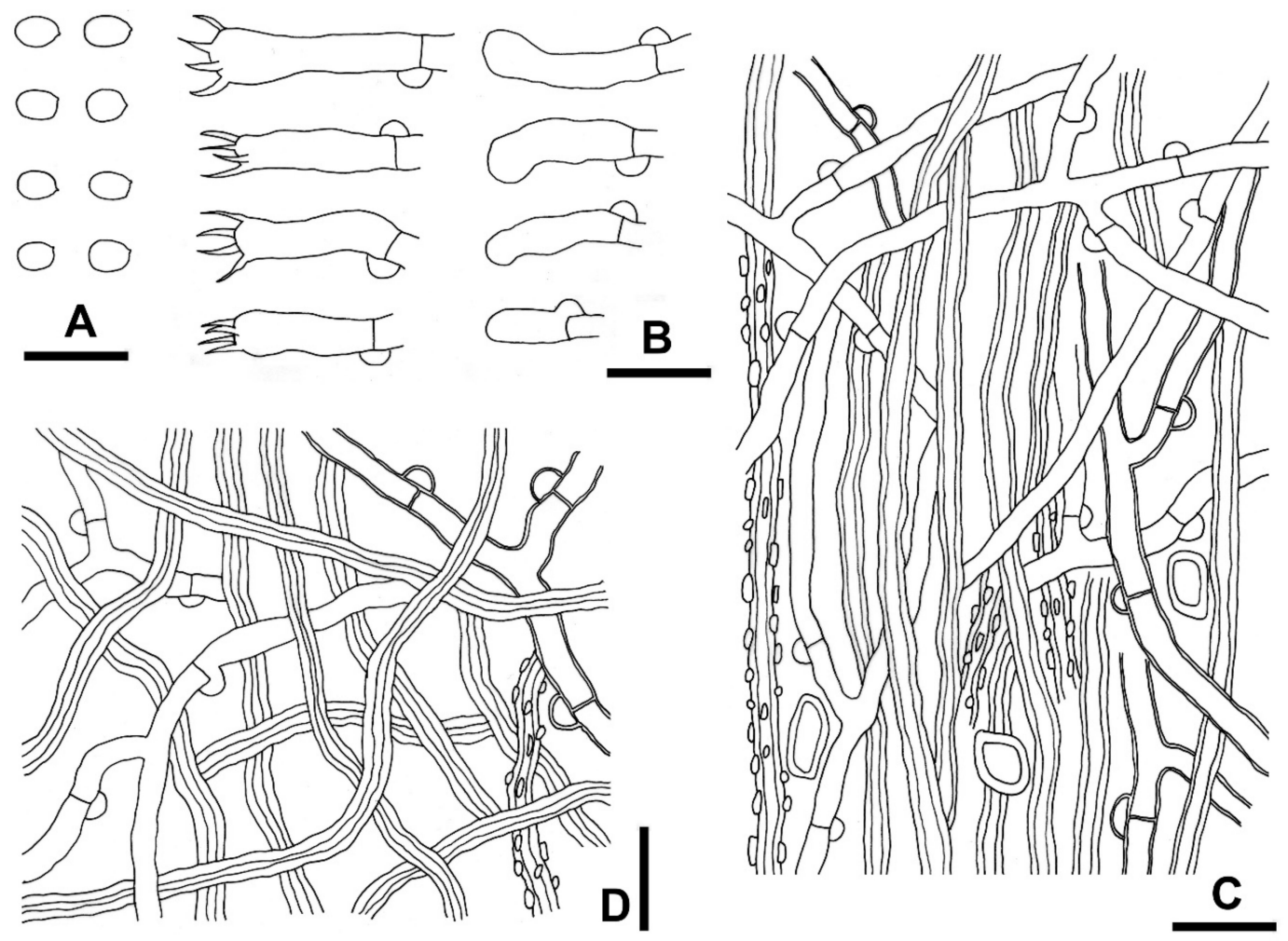

Figure 6. Microscopic structures of Fibrodontia subalba (drawn from the holotype). (A) Basidiospores; (B) basidia and basidioles; (C) hyphae from trama; (D) hyphae from subiculum. Scale bars: $(\mathbf{A}, \mathbf{B}, \mathbf{C}, \mathbf{D})=10 \mu \mathrm{m}$.

\section{MycoBank: MB 836339.}

Etymology: subalba (Latin), refers to the similarity to Fibrodontia alba.

Type: China, Xinjiang, Gongliu County, West Tianshan Mountain National Nature Reserve, $82^{\circ} 49^{\prime}$ E, $43^{\circ} 1^{\prime}$ N, on rotten wood of Populus, 14 Sept. 2015, Y.C. Dai, Dai 15,931 (holotype BJFC).

Description: Basidiocarps annual, resupinate, inseparable from substrate, without odor or taste, soft corky, and brittle when dry, up to $15 \mathrm{~cm}$ long, $10 \mathrm{~cm}$ wide and $1.7 \mathrm{~mm}$ thick. Hymenophore odontioid to hydnoid, darkening but otherwise unchanged in $\mathrm{KOH}$. Aculei orange white (5A2) when fresh, turning yellowish brown $[5 \mathrm{D}(4-6)]$ with age, greyish yellow [4B(3-4)] dry, 3-5 per mm, apically slightly fimbriate, up to $1.5 \mathrm{~mm}$ long. Subiculum white to cream, up to $0.2 \mathrm{~mm}$ thick. Margin white, cottony, up to $0.7 \mathrm{~mm}$ wide. Hyphal system dimitic; generative hyphae with clamp connections. Subiculum composed of a loose layer of distinct hyphae; generative hyphae, hyaline, thin- to slightly thick-walled, occasionally branched, smooth, 2-3.5 $\mu \mathrm{m}$ in diam; skeletal hyphae hyaline to yellowish, thick-walled with a wide to narrow lumen, unbranched, smooth or rarely encrusted with faceted crystals, more or less flexuous, loosely interwoven, 1.5-3 $\mu \mathrm{m}$ in diam. Aculei composed of a central 
core of compact hyphae and subhymenial and hymenial layers, at apex terminal hyphae slightly tapered; generative hyphae hyaline, thin- to slightly thick-walled, occasionally branched, smooth, interwoven, $2-4 \mu \mathrm{m}$ in diam; skeletal hyphae hyaline to yellowish, thick-walled with a wide lumen, unbranched, smooth or occasionally encrusted with faceted crystals, mainly straight, more or less parallel along the aculei, 1.5-3.5 $\mu \mathrm{m}$ in diam. Basidia suburniform to clavate, thin-walled, with four sterigmata and a clamp connection at base, 12-20 × 4-6 $\mu \mathrm{m}$; basidioles similar in shape to basidia, but smaller. Large rhomboid crystals present in subiculum and aculei. Basidiospores ellipsoid, hyaline, thin-walled, smooth, inamyloid, indextrinoid, acyanophilous, (3.5-)3.7-4.4(-4.6) $\times(2.7-) 2.8-3.4(-3.5) \mu \mathrm{m}$, $\mathrm{L}=4.0 \mu \mathrm{m}, \mathrm{W}=3.1 \mu \mathrm{m}, \mathrm{Q}=1.3(n=30 / 1)$.

Notes: Fibrodontia subalba is characterized by resupinate, odontioid to hydnoid basidiocarps with long aculei, a dimitic hyphal system with clamped generative hyphae and skeletal hyphae, absence of cystidia, and ellipsoid, hyaline, thin-walled, smooth basidiospores. Fibrodontia subalba is quite similar to $F$. alba but the latter species differs by denser (6-10 per $\mathrm{mm}$ ), shorter aculei (up to $0.4 \mathrm{~mm}$ long), and slightly narrower basidiospores (2.5-3.5 $\mu \mathrm{m}$ wide) [8]. Moreover, F. alba is reported from subtropical evergreen broad-leaved forests [8], whereas F. subalba is from a semiarid continental region. From other species of Fibrodontia, F. subalba is distinguished by its significantly longer aculei (up to $1.5 \mathrm{~mm}$ long).

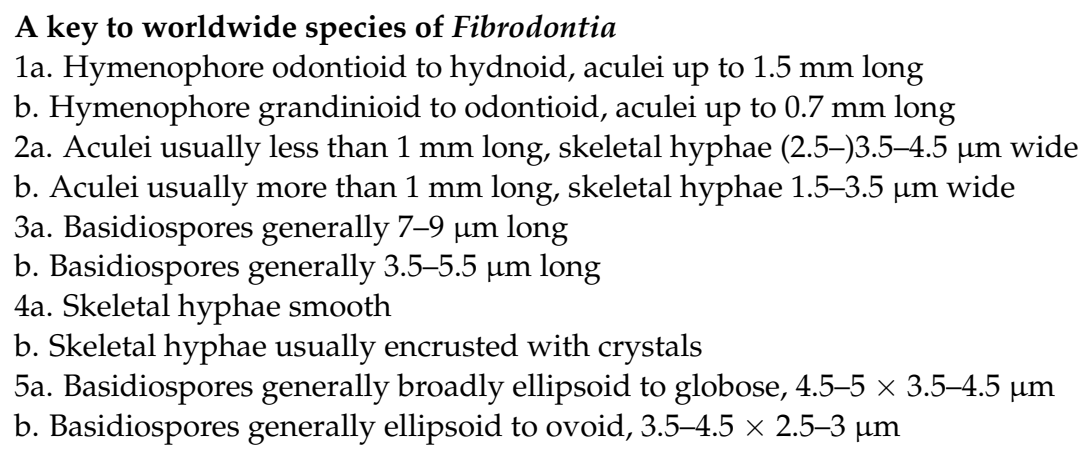

2
3
F. gossypina
F. subalba
F. tomentosa
4
F. austrosinensis
5
F. brevidens
F. alba

\section{Discussion}

In this study, two species of Fibrodontia from China, F. austrosinensis and F. subalba, are described as new species based on molecular analyses and morphological features. Phylogenetic analyses on five species of Fibrodontia presented above confirmed that Fibrodontia is a monophyletic genus in a strongly supported clade (Figure 1). Fibrodontia austrosinensis and F. subalba were clearly separated from other sampled species of Fibrodontia and from each other (Figures 1-3). Both mPTP and ABGD methods correspondingly confirmed the delimitation of the five sampled species of Fibrodontia (Figure 3). Moreover, based on ITS region (Table 2), intraspecific difference within specimens of $F$. alba was $1.17 \%$, whereas interspecific difference between sister taxa F. subalba and F. alba was $5.54 \%$. Similarly, interspecific sequence difference between sister taxa F. brevidens and F. austrosinensis was $5.30 \%$ compared to intraspecific differences of $0.06 \%$ and $0.12 \%$, respectively (Table 2 ).

The type of Fibrodontia brevidens was originally collected in Ecuador [7] and this species is considered to be widely distributed [9,30]. Ideally the sequences generated from samples in or close to type localities are included in phylogenetic analyses. However, the sequences of F. brevidens from South American samples are unavailable. Instead, in this study we used the sequences generated from Asian samples to represent $F$. brevidens following Yurchenko and $\mathrm{Wu}$ [8]. Molecular evidence supported F. brevidens as a distinct species within Fibrodontia (Figures 1-3; Table 2).

Fibrodontia tomentosa was absent from the current phylogeny. However, F. tomentosa is morphologically unique within this genus by its almost grandinioid hymenial surface, large rhomboid crystals present among hyphae, and cylindric to suballantoid basidiospores measured as 7-9 $\times 3.5-4.5 \mu \mathrm{m}[3,8]$. Fibrodontia tomentosa seems to be an uncommon species in tropical American countries and is so far known only from Cuba and Venezuela [3,7,31]. 
Baltazar et al. [32] studied the type of Cystidiodendron fimbriatum Rick and transferred it to Fibrodontia as F. fimbriata (Rick) Baltazar \& Rajchenb. Furthermore, they proposed that F. fimbriata and F. gossypina are conspecific based on their morphological features. If this synonym was confirmed, the monotypic genus Cystidiodendron Rick and its generic type C. fimbriatum, both introduced by Rick [33], would have priority over Fibrodontia (published in 1968), and thus all six species of Fibrodontia should be transferred to the genus Cystidiodendron. To keep taxonomic status of Fibrodontia stable, however, we do not propose any taxonomic changes related to this issue until molecular sequences from $C$. fimbriatum are available for phylogenetic analyses.

Author Contributions: S.-L.L., S.-H.H. and L.-W.Z. made morphological examinations. S.-L.L. and S.-H.H. performed molecular sequencing. S.-L.L. and L.-W.Z. performed phylogenetic analyses. S.-L.L., D.-M.L. and L.-W.Z. wrote the manuscript. L.-W.Z. conceived and supervised the work. All authors have read and agreed to the published version of the manuscript.

Funding: The research was financed by The Biodiversity Survey and Assessment Project of the Ministry of Ecology and Environment, China (No. 2019HJ2096001006), the National Natural Science Foundation of China (Project Nos. 31770008, 31870011, and 31570014) and Youth Innovation Promotion Association of the Chinese Academy of Sciences (No. 2017240).

Data Availability Statement: Publicly available datasets were analyzed in this study. All resulting alignments were deposited in TreeBASE (http:/ / www.treebase.org; accession number S27597). All newly generated sequences were deposited in GenBank (https://www.ncbi.nlm.nih.gov/genbank/; Table 1). All new taxa were deposited in MycoBank (https://www.mycobank.org/; MycoBank identifiers follow new taxa).

Acknowledgments: Yu-Cheng Dai (BJFC, China) is thanked for forwarding specimens on loan. Juliano M. Baltazar (Universidade Federal de São Carlos, Brazil) is appreciated for helpful discussion.

Conflicts of Interest: The authors declare no conflict of interest. The funders had no role in the design of the study; in the collection, analyses, or interpretation of data; in the writing of the manuscript, or in the decision to publish the results.

\section{References}

1. Parmasto, E. Conspectus systematis Corticiacearum; Institutum Zoologicum et Botanicum Academiae Scientiarum R.P.S.S.: Tartu, Estonia, 1968; pp. 1-97.

2. Eriksson, J.; Hjortstam, K.; Ryvarden, L. The Corticiaceae of North Europe: Phlebia—Sarcodontia; Grønlands Eskefabrikk: Oslo, Norway, 1981; Volume 6, pp. 1051-1276.

3. Langer, E. Die Gattung Hyphodontia John Eriksson. Bibl. Mycol. 1994, 154, 1-298.

4. Binder, M.; Hibbett, D.S.; Larsson, K.H.; Larsson, E.; Langer, E.; Langer, G. The phylogenetic distribution of resupinate forms across the major clades of mushroom-forming fungi (Homobasidiomycetes). Syst. Biodivers. 2005, 3, 113-157. [CrossRef]

5. Larsson, K.H. Re-thinking the classification of corticioid fungi. Mycol. Res. 2007, 111, 1040-1063. [CrossRef]

6. Wang, X.W.; May, T.W.; Liu, S.L.; Zhou, L.W. Towards a natural classification of Hyphodontia sensu lato and the trait evolution of basidiocarps within Hymenochaetales (Basidiomycota). J. Fungi 2021, 7, 478. [CrossRef]

7. Hjortstam, K.; Ryvarden, L.; Iturriaga, T. Studies in corticioid fungi from Venezuela II (Basidiomycotina, Aphyllophorales). Synop. Fungorum 2005, 20, 42-78.

8. Yurchenko, E.; Wu, S.H. Fibrodontia alba sp. nov. (Basidiomycota) from Taiwan. Mycoscience 2014, 55, 336-343. [CrossRef]

9. Yurchenko, E.; Wu, S.H. New Asian records and morphological variation in Fibrodontia brevidens (Basidiomycota). Mycotaxon 2012, 122, 293-301. [CrossRef]

10. Liu, S.L.; Ma, H.X.; He, S.H.; Dai, Y.C. Four new corticioid species in Trechisporales (Basidiomycota) from East Asia and notes on phylogeny of the order. MycoKeys 2019, 48, 97-113. [CrossRef]

11. Kornerup, A.; Wanscher, J.H. Methuen Handbook of Colour, 3rd ed.; Eyre Methuen: London, UK, 1978; pp. 1-252.

12. Wang, X.W.; Jiang, J.H.; Zhou, L.W. Basidioradulum mayi and B. tasmanicum spp. nov. (Hymenochaetales, Basidiomycota) from both sides of Bass Strait, Australia. Sci. Rep. 2020, 10, 102. [CrossRef]

13. White, T.J.; Bruns, T.; Lee, S.; Taylor, J. Amplification and direct sequencing of fungal ribosomal RNA genes for phylogenetics. In PCR Protocols: A Guide to Methods and Applications; Innis, M.A., Gelfand, D.H., Sninsky, J.J., White, T.J., Eds.; Academic Press: San Diego, CA, USA, 1990; pp. 315-322.

14. Vilgalys, R.; Hester, M. Rapid genetic identification and mapping of enzymatically amplified ribosomal DNA from several Cryptococcus species. J. Bacteriol. 1990, 172, 4238-4246. [CrossRef] [PubMed] 
15. Rehner, S.A.; Buckley, E. A Beauveria phylogeny inferred from nuclear ITS and EF1- $\alpha$ sequences: Evidence for cryptic diversification and links to Cordyceps teleomorphs. Mycologia 2005, 97, 84-98. [CrossRef]

16. Liu, Y.L.; Whelen, S.; Hall, B.D. Phylogenetic relationships among ascomycetes: Evidence from an RNA polymerase II subunit. Mol. Biol. Evol. 1999, 16, 1799-1808. [CrossRef]

17. Matheny, P.B. Improving phylogenetic inference of mushrooms with RPB1 and RPB2 nucleotide sequences (Inocybe, Agaricales). Mol. Phylogenet. Evol. 2005, 35, 1-20. [CrossRef] [PubMed]

18. Katoh, K.; Standley, D.M. MAFFT multiple sequence alignment software version 7: Improvements in performance and usability. Mol. Biol. Evol. 2013, 30, 772-780. [CrossRef] [PubMed]

19. Katoh, K.; Kuma, K.; Toh, H.; Miyata, T. MAFFT version 5: Improvement in accuracy of multiple sequence alignment. Nucleic Acids Res. 2005, 33, 511-518. [CrossRef] [PubMed]

20. Guindon, S.; Gascuel, O. A simple, fast and accurate algorithm to estimate large phylogenies by maximum likelihood. Syst. Biol. 2003, 52, 696-704. [CrossRef]

21. Darriba, D.; Taboada, G.L.; Doallo, R.; Posada, D. jModelTest 2: More models, new heuristics and parallel computing. Nat. Methods 2012, 9, 772. [CrossRef]

22. Ronquist, F.; Teslenko, M.; van der Mark, P.; Ayres, D.L.; Darling, A.; Höhna, S.; Larget, B.; Liu, L.; Suchard, M.A.; Huelsenbeck, J.P. MrBayes 3.2: Efficient Bayesian phylogenetic inference and model choice across a large model space. Syst. Biol. 2012, 61, 539-542. [CrossRef]

23. Rambaut, A.; Drummond, A.J.; Xie, D.; Baele, G.; Suchard, M.A. Posterior summarisation in Bayesian phylogenetics using Tracer 1.7. Syst. Biol. 2018, 67, 901-904. [CrossRef] [PubMed]

24. Stamatakis, A. RAxML-VI-HPC: Maximum likelihood-based phylogenetic analyses with thousands of taxa and mixed models. Bioinformatics 2006, 22, 2688-2690. [CrossRef]

25. Edler, D.; Klein, J.; Antonelli, A.; Silvestro, D. RaxmlGUI 2.0: A graphical interface and toolkit for phylogenetic analyses using RAxML. Methods Ecol. Evol. 2021, 12, 373-377. [CrossRef]

26. Pattengale, N.D.; Alipour, M.; Bininda-Emonds, O.R.P.; Moret, B.M.E.; Stamatakis, A. How many bootstrap replicates are necessary? J. Comput. Biol. 2010, 17, 337-354. [CrossRef]

27. Zhang, J.; Kapli, P.; Pavlidis, P.; Stamatakis, A. A general species delimitation method with applications to phylogenetic placements. Bioinformatics 2013, 29, 2869-2876. [CrossRef] [PubMed]

28. Puillandre, N.; Lambert, A.; Brouillet, S.; Achaz, G. ABGD, Automatic Barcode Gap Discovery for primary species delimitation. Mol. Ecol. 2012, 21, 1864-1877. [CrossRef] [PubMed]

29. Kumar, S.; Stecher, G.; Li, M.; Knyaz, C.; Tamura, K. MEGA X: Molecular evolutionary genetics analysis across computing platforms. Mol. Biol. Evol. 2018, 35, 1547-1549. [CrossRef] [PubMed]

30. Ryvarden, L. Studies in the Aphyllophorales of Africa 6. Some species from eastern Central Africa. Bull. Jard. Bot. Natl. Belg. 1978, 48, 79-119. [CrossRef]

31. Berkeley, M.J.; Curtis, M.A. Fungi Cubenses (Hymenomycetes). J. Linn. Soc. Bot. 1869, 10, 280-392. [CrossRef]

32. Baltazar, J.M.; Silveira, R.M.B.; Rajchenberg, M. Type studies of J. Rick's corticioid homobasidiomycetes (Agaricomycetes, Basidiomycota) housed in the Herbarium Anchieta (PACA). Phytotaxa 2016, 255, 101-132. [CrossRef]

33. Rick, J. Recensentur fungi resupinati rari et novi Americae meridionalis. Lilloa 1943, 9, 215-219. 